\title{
Planning of births and childhood undernutrition in Nepal: evidence from a 2016 national survey
}

\author{
Ishwar Tiwari ${ }^{1 *} \mathbb{D}$, Kiran Acharya ${ }^{2}$, Yuba Raj Paudel ${ }^{3}$, Bhim Prasad Sapkota ${ }^{4,5}$ and Ramesh Babu Kafle ${ }^{6}$
}

\begin{abstract}
Background: Childhood undernutrition is a significant public health issue in low-and middle-income countries, including Nepal. However, there is limited evidence showing the association between the planning of birth (PoB) and childhood undernutrition (stunting and underweight). We aimed to investigate the relationship between PoB and childhood undernutrition in the current study.
\end{abstract}

Methods: We used the Nepal Demographic and Health Survey (NDHS) 2016 data, a nationally representative crosssectional household survey. We used two anthropometric indicators of childhood undernutrition as the outcome of this study. PoB is the main predictor. We used binary logistic regression with sampling weights to estimate adjusted odds ratios (ORs) and 95\% confidence intervals ( $\mathrm{Cls}$ ) to examine the association between the PoB and childhood undernutrition. Unless stated, the significant association between the variables is calculated with $p<0.001$.

Results: The overall prevalence of stunting was $35.8 \%$, and underweight was $27.1 \%$ in children under 5 years of age in Nepal. We found a higher rate of stunting (52.7\%) and underweight (41.1\%) in children with birth order $>3$ and $<2$ years of the interval between birth and subsequent birth (IBBSB). The association between the children's birth order and the prevalence of undernutrition had strong statistical significance. Mother's age at marriage ( $p=$ 0.001), underweight mother, mother's education, father's education, wealth quintile, no exposure to mass media, children's age, and place of residence $(p=0.001)$ were significantly associated with childhood undernutrition. The result of the multiple logistic regression showed that children with birth order one and 12-24 months of the interval between marriage and first birth (IBMFB) had significantly decreased odds of stunting than those children with birth order one and $<12$ months of IBMFB (OR 0.6, 95\% Cl 0.4-0.9).

Conclusion: The findings of the study demonstrate that PoB has a protective effect on childhood undernutrition. Delaying of childbirth until 12-24 months after marriage was found to be associated with reduced childhood stunting odds. To mitigate childhood undernutrition, Nepal's government needs to promote delayed childbearing after marriage while focusing on uplifting the household economics status and wide coverage of and utilization of mass media.

Keywords: Planning of birth, Undernutrition, Stunting, Underweight, Nepal

\footnotetext{
* Correspondence: Ishwar.tiwari92@gmail.com

${ }^{1}$ Health for Life, RTI International, Kathmandu, Nepal

Full list of author information is available at the end of the article
}

(C) The Author(s). 2020 Open Access This article is licensed under a Creative Commons Attribution 4.0 International License, which permits use, sharing, adaptation, distribution and reproduction in any medium or format, as long as you give appropriate credit to the original author(s) and the source, provide a link to the Creative Commons licence, and indicate if changes were made. The images or other third party material in this article are included in the article's Creative Commons licence, unless indicated otherwise in a credit line to the material. If material is not included in the article's Creative Commons licence and your intended use is not permitted by statutory regulation or exceeds the permitted use, you will need to obtain permission directly from the copyright holder. To view a copy of this licence, visit http://creativecommons.org/licenses/by/4.0/ The Creative Commons Public Domain Dedication waiver (http://creativecommons.org/publicdomain/zero/1.0/) applies to the data made available in this article, unless otherwise stated in a credit line to the data. 


\section{Background}

Childhood undernutrition is a significant public health issue globally. It is estimated that among children under 5 years of age, one-third are stunted (178 million), and 112 million are underweight [1]. Childhood undernutrition accounts for more than half of the global deaths in children younger than 5 years of age $[2,3]$. It causes a substantial increase in overall disease burden, particularly in low-and middle-income countries, including Nepal [2, 3].

The government of Nepal (GoN) has made a clear commitment to addressing undernutrition, including childhood undernutrition in Nepal [4]. Nepal signed up to the global Scaling Up Nutrition (SUN) movement in 2011, agreed upon by the World Health Assembly (WHA) in 2012 [5]. The SUN movement aimed at a 40\% reduction in global stunting among children under 5 years of age by 2025 [6]. Currently, Nepal's annual average rate of reduction (AARR) of stunting is 0.031 , but it needs to maintain an AARR of 0.043 to achieve the global target of stunting in children under 5 years of age [7]. Nepal endorsed a multi-sector approach for nutrition and prioritized improving child nutrition in its fiveyear Multi-sector Nutrition Plan (MSNP) 2013-2017 [8]. The Government of Nepal is committed to the declaration of the United Nations (UN) General Assembly' 2016-2025 period as the decade of action on nutrition' [9]. In 2017, Nepal endorsed MSNP 2018-2022 and renewed its commitment to nutrition [7]. Nepal also supports internationally agreed targets; specifically, the Sustainable Development Goal (SDG) target 2.2 on ending all forms of malnutrition by $2030[10,11]$. SDG 2 targets to reduce the prevalence of undernourishment to $3 \%$ and underweight prevalence to $5 \%$ in children under 5 years of age by 2030 [5]. All the national nutritional targets of Nepal are also aligned with the Global Nutrition Targets [4].

Department of health service (DoHS), under the Ministry of Health and Population (MoHP), Nepal, executes several national-level nutrition programs, such as Vitamin A supplementation, growth monitoring, Infant and young child feeding (IYCF), iron supplementation, iodine fortification. Under the common framework of MSNP, the GoN has also initiated several large-scale, multisector, integrated nutrition projects and programs, with support from its development partners. For example, Nepal started United States Agency for International Development (USAID) supported SUAAHARA (Good nutrition) projects, KISAN (Knowledge-based Integrated Sustainable Agriculture in Nepal), and SABAL (Sustainable Action for Resilience and Food Security); World Bank-supported Sunaulo Hazar din (Golden 1000 days); European Union and the United Nations International Children Emergency Fund (UNICEF) supported Maternal and Young Child Nutrition Security Initiative in Asia(2011-2015) and Poshan ko Lagi Hatemalo (Partnership for Improved Nutrition) (2016-2019) [4]. Such an aggressive implementation of the nutrition-specific program has contributed to a progressive decline in the prevalence of undernutrition in children under 5 years of age in Nepal. In 2006, stunting was was $49 \%$, which decreased to $41 \%$ in 2011 , and $36 \%$ in 2016 [12-14]. Underweight also reduced from $39 \%$ in 2006 to $29 \%$ in 2011 and $27 \%$ in 2016 [12-14]. However, Nepal has still a considerable prevalence rate of stunting and underweight in children under 5 years of age.

Family planning has a positive influence on child health and nutritional outcomes [15]. It allows a couple to plan the timing of their childbirth, the number of deliveries, and the childbirth spacing $[15,16]$.

Previous studies have shown that shorter birth spacing and frequent childbearing cause adverse effects not only on maternal and child health but also lead to poor nutritional outcomes [15, 17-19]. Childbearing at a younger age also causes poor nourishment of children [20]. Therefore, some international agencies have advocated empowering women to partake in family planning, which also supports to improve maternal, infant, and young child nutrition [20]. For example, SUAAHARA (Good Nutrition) program in Nepal advocates for women empowerment and has integrated family planning as one of the eight essential nutrition actions to promote maternal and child nutrition $[21,22]$. The theory of change of MSNP-II 2018-2022 has also accepted family planning and reproductive health services to achieve nutritional targets under the health sector response [7]. Although family planning may contribute to better nutrition outcomes in under-five children, it has received little attention in low-and middle-income countries [23]. Only a few global studies exist which have investigated the relationship between family planning and childhood undernutrition [15, 20, 23-25]. Nepal's National Nutrition Policy and Strategy 2004 (revised in 2008) and National Health Policy 2019 are the leading policy documents guiding nutritional interventions in the health sectors. Still, both documents are unaware of the relationship between $\mathrm{PoB}$ and nutritional outcomes of children due to the lack of stringent evidence. Therefore, this paper aims to examine the association between $\mathrm{PoB}$ and undernutrition in children under 5 years of age in Nepal.

\section{Methods}

\section{Data source}

We used data from the NDHS conducted in 2016. NDHS is a nationally representative cross-sectional household survey conducted every 5 years. For the 2016 NDHS, the survey sample of 12,862 is representative at 
the national and provincial levels, for ecological zones and development regions, and the urban and rural areas [14]. The 2016 NDHS used the sampling frame from the 2011 National Population and Housing Census (NPHC), which was conducted by the Central Bureau of Statistics (CBS). The details of the sampling procedure are available elsewhere [14]. The survey collected a broad range of socioeconomic, demographic, and health data from all eligible men and women of age group 15-49 by administering six well-structured and standardized questionnaires (the household questionnaire, the woman's questionnaire, the man's questionnaire, the biomarker questionnaire, the fieldworker questionnaire, and the verbal autopsy questionnaire for neonatal death). All questionnaires were first finalized in English and then translated into Nepali, Maithili, and Bhojpuri. ICF Institutional Review Board (IRB) reviewed the survey. The survey also received ethical approval from the Nepal Health Research Council (NHRC). All interviewers underwent 2 weeks of a training course using a standard protocol manual, followed by 1 week of Computer Assisted Personal Interview (CAPI) training before data collection [26]. Written consent was sought from each participant following the NHRC guidelines. The 2016 NDHS yielded a response rate of $99 \%$.

\section{Definition of variables}

We considered two common anthropometric indicators of undernutrition, namely stunting (low height-for-age) and underweight (low weight-for-age), as the outcome variables for this study. As per the World Health Organization (WHO) criteria, children with less than negative two $(<-2)$ standard deviation.

(SD) below the mean are considered as stunted and underweight [27]. We used normalized z-scores in the NDHS dataset for height-for-age and weight-for-age.

For this study, the main predictor of interest is PoB, which is composed of the intersectional axes of birth order, the interval between marriage and first birth (IBMFB), and the interval between births and subsequent births (IBBSB). We categorized the birth order into three categories: one, $2-3$, and $>3$. We grouped IBMFB into < 12 months, $12-24$ months, $25-36$ months, and more than 36 months for the first order birth. For birth order 2-3 and $>3$, we divided IBBSB into $\leq 24$ months and $>24$ months. In total, we created eight intersectional axes of the PoB.

\section{Selection of study sample}

The survey identified 5060 children under 5 years of age, of which 4887 were alive and 173 were dead. After excluding missing cases whose valid date of birth and valid measurement of both height and weight were not reported, NDHS reported 2421 stunted children and 2428 underweight children. The difference between the stunting and underweight sample size was due to the difference of flagged/missing cases in height and weight measurements. We dropped seven denominator cases used in low weight-for-age, i.e., underweight, to make it consistent with the total number of children, i.e., the denominator used in stunted (Fig. 1). We also excluded the child whose biological mother was not interviewed. Thus, our final study sample included 2355 children (for both stunting and underweight) for the analysis based on the inclusion criteria: children who have valid data of age, weight, height, and whose biological mother was interviewed.

\section{Statistical analysis}

We used STATA version 15.0 to conduct data analyses. Descriptive analysis of the outcome and covariates are shown in the table. We performed a chi-square test to assess the association between the predictors and outcome variables. We conducted a binary logistic regression to examine the association between $\mathrm{PoB}$ and childhood undernutrition. We controlled for the potential confounding variables in the analysis, such as mother's age at marriage in years, mother's current age in years, mother's BMI, mother's anemia, caste, mother's education, father's education, place of residence, mother's occupation, wealth quintile, exposure to mass media, sex of the children, age of the children in months, place of residence, ecological region, province, and household food security. Adjusted ORs and 95\% CIs were calculated to show the effect and significance of the association. We checked the collinearity effect among the predictors and investigated the potential interaction of the PoB with maternal nutrition and wealth quintile. We considered a $p$-value $<0.05$ and $95 \%$ CIs for the significant relationship between the exposure and outcome variables. We presented the weighted figures to adjust for variations in the selection probabilities and interviews among participants. We also utilized the "Svy" command to account for complex survey design and provide unbiased estimates.

\section{Results \\ Descriptive results}

Table 1 presents the descriptive characteristics of the study population. The frequency distribution table shows the highest percentage of order 2-3 children (45.7\%), with $35.1 \%$ of them having more than 24 months of the interval between birth and subsequent birth (IBBSB). $64.1 \%$ of the mothers were married at the age of 15 to 19 years, with a mean age at marriage of 17.7 years. Approximately two-thirds of the mothers $(65.4 \%)$ had normal basal metabolic index (BMI), and more than half of 


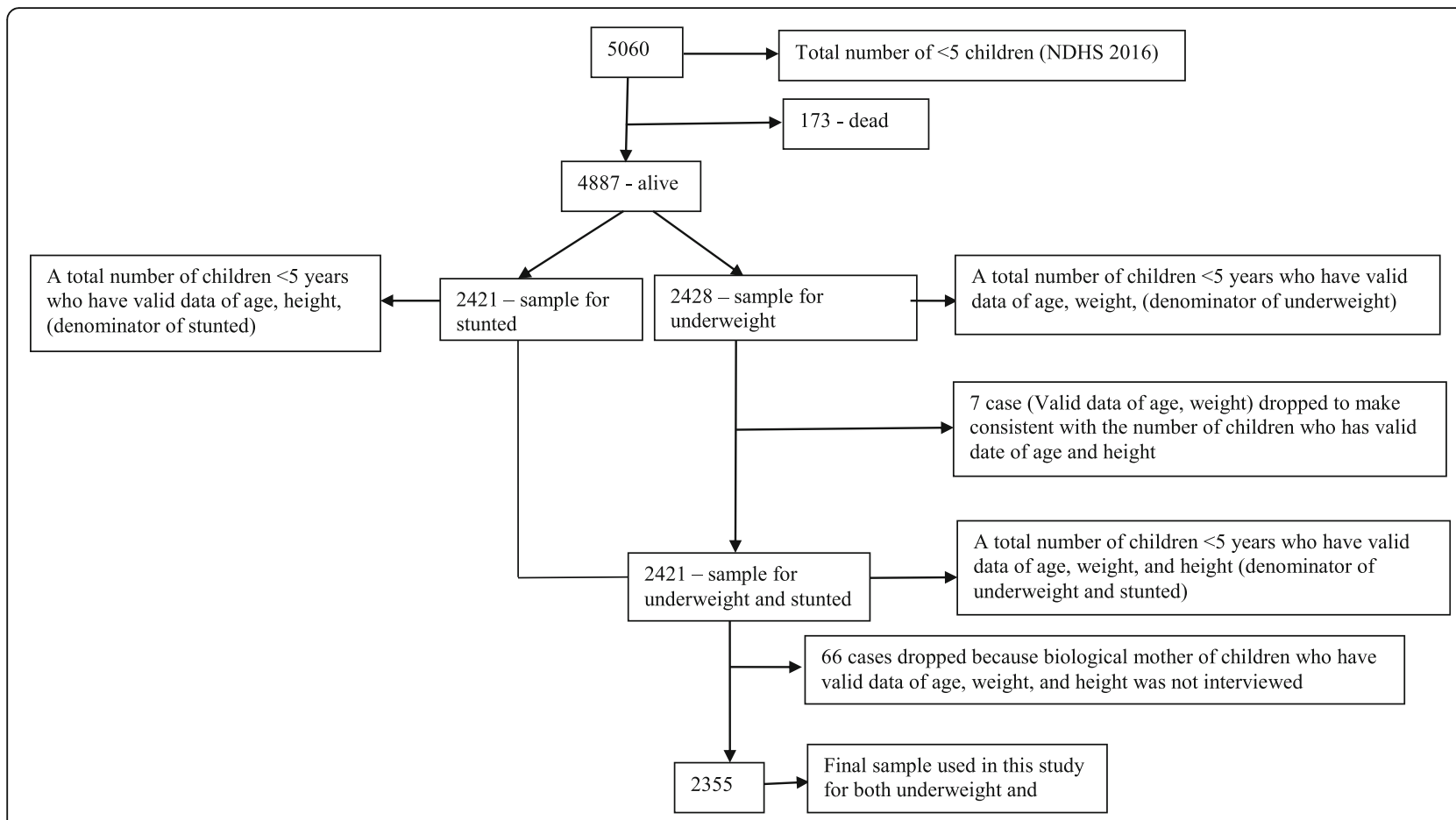

Fig. 1 Flowchart of the study sample

the mothers (54.2\%) of the children were not anemic. A considerable proportion of mothers who participated in the study were illiterate (34.6\%), and $45.3 \%$ of the mothers had at least secondary education. Almost half of the mothers $(46.2 \%)$ lived on agriculture. The male children's share was slightly higher (52.2\%) than female children $(47.8 \%)$ in the survey.

The representation of the study population by area of residence was quite similar (urban-52.6\% and rural47.4\%). Newar and Janajatis represented the largest percentage $(31.1 \%)$ of the study participants, while Muslims/others had the least representation (7.5\%) in the present study. The distribution of the study population was nearly uniform, around $21 \%$ for all categories of wealth quintile except the richest category, which was as low as $13.2 \%$. Most children represented Province 2 (27.4\%), while Province 6 had the least percentage of children who participated in the study. A total of $41 \%$ of the household were food secure, while only $10.5 \%$ were facing severe food insecurity.

\section{Rate of stunting and underweight and $\mathrm{PoB}$}

The present study found a substantial percentage of children with undernutrition (stunting-35.8\% and underweight27.1\%) (Table 2). We observed a relatively higher rate of stunting (52.7\%) and underweight (41.1\%) in children with birth order $>3$ and $<2$ years of IBBSB, followed by birth order 2-3 children and $<2$ years of IBBSB (stunting- $41.5 \%$ and underweight-32.3\%). The association between the birth order of children and the prevalence of undernutrition was highly significant.

Mothers who were in the age group 35-49 at the time of the survey had the highest prevalence of child stunting (42.6\%) and showed a significant association. Children born to the mothers in the age category of 30-34 years had the highest prevalence of underweight (30.4\%) but did not show significant association. Mother's age at marriage less than 15 years (stunted$42.4 \%$ and underweight-33.4\%), underweight women (stunted-44.5\% and underweight-42.7\%), mother's illiteracy (stunting-45.8\% and underweight-36.8\%), father's illiteracy (stunting-46.3\% and underweight$38.1 \%$ ), poorest wealth quintile (stunted-49.1\% and underweight-33.0\%), no exposure to mass media (stunted$50.5 \%$ and underweight-39.7\%), children's age group 24-35 months (stunted $44.8 \%$ and underweight-31.1\%), and rural residence (stunted-40.2\% and underweight-31.0\%) were the significant predictors of childhood undernutrition.

\section{Factors associated with stunting}

Multiple logistic regression showed that children with birth order 1 and 12-24 months of IBMFB had 0.6 times significantly lower odds of being stunted than children with birth order one and $<12$ months of IBMFB (Table 3). None of the other birth orders and birth intervals showed a significant association with stunting (Table 3). Mothers in the age group 20-24 years had significantly lower odds of having stunted children than 
Table 1 Descriptive statistics of the study population

\begin{tabular}{l} 
Variables \\
\hline Planning of births ${ }^{\text {a }}$ \\
Order $1 \&<12$ month of IBMFB \\
Order $1 \& 12-24$ months of IBMFB \\
Order $1 \& 25-36$ months of IBMFB \\
Order $1 \&>36$ months of IBMFB \\
Order $2-3 \&<=24$ months of IBBSB \\
Order $2-3 \&>24$ months of IBBSB \\
Order $>3 \&<=24$ months of IBBSB \\
Order $>3 \&>24$ months of IBBSB \\
Mother's age at marriage in years \\
$<15$ \\
15-19 \\
20-24 \\
25-40 \\
Mean age (sd) = 17.7 (3.3)
\end{tabular}

Mother's current age in years

$\begin{array}{lll}15-19 & 8.3 & 195 \\ 20-24 & 34.2 & 804 \\ 25-29 & 32.6 & 767 \\ 30-34 & 15.7 & 369 \\ 35-49 & 9.3 & 220\end{array}$

Mean age $(s d)=26.3(5.7)$

\section{Mother's BMI ${ }^{\mathrm{a}}$}

Normal

Underweight

Obese

\section{Mother's anemia ${ }^{a}$}

Not anemic

Anemic

\section{2}

45.8

\section{Caste}

Brahmin/Chettri
Terai/Madhesi other
Dalit
Newar/Janajatis
Muslim/other

Mother's education

Illiterate

Primary

Secondary

Higher

\section{Father's education ${ }^{2}$}

|lliterate

Primary
Table 1 Descriptive statistics of the study population (Continued)

\begin{tabular}{lll}
\hline Variables & Percentage & $\begin{array}{l}\text { Frequency } \\
(\boldsymbol{n}=\mathbf{2 3 5 5})\end{array}$ \\
\hline $\begin{array}{l}\text { Secondary } \\
\text { Higher }\end{array}$ & 44.2 & 1033 \\
Mother's occupation & 17.5 & 408 \\
$\quad$ Not working & & \\
Agriculture & 39.7 & 935 \\
Paid jobs & 46.2 & 1089 \\
Wealth quintile & 14.1 & 331 \\
$\quad$ Poorest & & \\
Poorer & 20.6 & 486 \\
Middle & 21.8 & 513 \\
Richer & 22.7 & 535 \\
Richest & 21.6 & 510 \\
& 13.2 & 311
\end{tabular}

Exposure to mass media (newspaper/radio/television)

Not at all

23.1

545

Less than once a week

47.5

1118

At least once a week

29.4

692

Sex of the children

Male

52.3

1231

Female

47.7

1124

Age of the children

$0-11$ months

465

12-23 months

19.8

21.6

508

24-35 months

446

36-47 months

476

48-59 months

460

Mean age $(s d)=29.4(17.2)$

Place of residence

Urban

52.6

1239

Rural

47.4

1117

Ecological region

$\begin{array}{lll}\text { Mountain } & 7.0 & 164 \\ \text { Hill } & 36.6 & 861 \\ \text { Terai } & 56.5 & 1330\end{array}$

Province

$\begin{array}{lll}\text { Province 1 } & 16.1 & 379 \\ \text { Province 2 } & 27.4 & 645 \\ \text { Province 3 } & 14.8 & 349 \\ \text { Province 4 } & 7.7 & 182 \\ \text { Province 5 } & 18.9 & 445 \\ \text { Province 6 } & 6.4 & 151 \\ \text { Province 7 } & 8.6 & 204\end{array}$


Table 1 Descriptive statistics of the study population (Continued)

\begin{tabular}{lll}
\hline Variables & Percentage & $\begin{array}{l}\text { Frequency } \\
(\boldsymbol{n}=\mathbf{2 3 5 5})\end{array}$ \\
\hline Household food security & & \\
Food secure & 41 & 965 \\
Mild food insecure & 22.7 & 535 \\
Moderate food insecure & 25.8 & 609 \\
Severe food insecure & 10.5 & 247 \\
\hline
\end{tabular}

${ }^{a}$ number of cases missed from the variable:

Planning of birth- 8

Mother's BMI- 4

Mother's anemia- 15

Father's education- 19

mothers in the age group $<15$ years. Obese mothers had decreased odds of child stunting than mothers with normal BMI. The relationship was statistically significant. However, the relationship between underweight mothers and child stunting was not significant. Mothers with paid jobs had significantly higher odds of stunted children than mothers who were not working. All categories of wealth quintile (poorer, middle, richer, and richest) had significantly lower odds of child stunting than those who were in the poorest quintile. Exposure to mass media also had significantly decreased odds of stunting than those who did not have exposure at all. The odds ratio was 0.6 for those who were exposed less than once a week. For those who were exposed at least once a week, the odds ratio was again 0.6. We observed highly significant greater odds of stunting in all age categories of the children than the $0-11$ months age category. At the administrative level, Province 6 had greater odds of stunting than Province 1.

\section{Factors associated with underweight}

Table 4 presents the results of the logistic regression analysis for the odds of underweight in under-five children. Any category of $\mathrm{PoB}$ did not show a statistically significant relationship with underweight than first-order birth and less than 12 months of IBMFB. Underweight mothers were 1.7 times more likely to have underweight children than mothers with normal BMI. In contrast, obese mothers had significantly lower odds of underweight children than mothers with normal BMI. Poorer, richer, and richest category of wealth quintile showed significantly lower odds of underweight children than the poorest quintile. We also observed significantly higher odds of underweight children in the age group 12-23 months, 24-35 months, and 48-59 months than children in the $0-11$ months category. At ecological division, the Terai region had 1.8 times higher odds of underweight children than the mountain region. The relationship was statistically significant.

\section{Interaction of PoB with maternal nutrition and wealth quintile}

We tested for the interaction effect of PoB with maternal anemia for both stunting and underweight separately (not shown in the table). We also examined the interaction between PoB and household wealth quintile. We did not observe any significant interaction.

\section{Discussion}

In the present study, we found that the rate of stunting and underweight in children under 5 years of age increased significantly with an increase in birth order and shorter birth interval. However, the overall result of multivariate logistic regression did not specifically show a significant relationship between the PoB and undernutrition. We found that younger age at marriage, poor socioeconomic characteristics of the mother, area of residence were significantly associated with childhood undernutrition.

\section{Rate of stunting and underweight and PoB}

The stunting rate and underweight rate of children under 5 years of age in Nepal are quite similar to the national stunting rate and underweight rate in children under 5 years of selected South Asian countries. Pakistan DHS 2017/18 reported an overall stunting rate of 37.6\% and an underweight rate of $23 \%$ [28]. The stunting rate and underweight rate in Bangladesh were 31 and 22\%, respectively, as per Bangladesh DHS 2017/18 [29]. In contrast, the prevalence rate of stunting and underweight in children under 5 years of age in the Maldives is relatively less than the prevalence rate in other South Asian countries. Maldives DHS 2016/17 reported an only national prevalence rate of $15.3 \%$ stunting and $15 \%$ underweight [30]. The continuous decline in the prevalence of childhood undernutrition in Nepal since 2001 can be attributed to the rigorous implementation of several large-scale nutrition-specific projects and programs led by GoN, with the help of development partners.

This study showed that the prevalence of stunting and underweight increases with higher birth order and shorter birth intervals. This finding was consistent with previous studies that sought to examine the relationship between PoB and childhood undernutrition. For example, a retrospective analysis of the National Family Health Survey (NFHS) 2015/16 data of India also reported the highest rate of stunting $(53.1 \%)$ and underweight $(48.4 \%)$ in children with birth order $>3$ and $<3$ years of IBBSB [15]. Rana et al. found a lower risk for stunting $(20 \% ; p<0.01)$ and underweight $(14 \% ; p<0.05)$ in the first birth order with $>24$ months of IBMFB in their retrospective study that analyzed DHS data of selected South Asia countries (Nepal, India, Bangladesh, and Pakistan) [20]. A retrospective study analyzing a 
Table 2 Rate of stunting and underweight by predictors

\begin{tabular}{|c|c|c|c|c|c|c|}
\hline Variables & Stunting (\%) & $95 \% \mathrm{Cl}$ & $p$-value & Underweight (\%) & $95 \% \mathrm{Cl}$ & $p$-value \\
\hline Total & 35.8 & $33.4,38.3$ & & 27.1 & $24.7,29.7$ & \\
\hline \multicolumn{7}{|l|}{ Planning of births } \\
\hline Order $1 \&<12$ month of IBMFB & 36.7 & $29.6,44.5$ & $p=0.000$ & 19.1 & $13.7,25.9$ & $p=0.000$ \\
\hline Order 1 \& 12-24 months of IBMFB & 28.6 & $24.0,33.6$ & & 24.6 & $20.0,29.9$ & \\
\hline Order 1 \& 25-36 months of IBMFB & 30.7 & $23.3,39.3$ & & 23.5 & $16.2,32.8$ & \\
\hline Order $1 \&>36$ months of IBMFB & 25.0 & $18.2,33.3$ & & 16.9 & $10.9,25.3$ & \\
\hline Order $2-3 \&<=24$ months of IBBSB & 41.5 & $35.2,48.2$ & & 32.3 & $26.2,39.0$ & \\
\hline Order 2-3 \& > 24 months of IBBSB & 34.1 & $30.5,38.0$ & & 24.7 & $21.2,28.5$ & \\
\hline Order $>3 \&<=24$ months of IBBSB & 52.7 & $41.5,63.5$ & & 41.1 & $30.9,52.1$ & \\
\hline Order $>3 \&>24$ months of IBBSB & 46.8 & $40.0,53.6$ & & 40.4 & $33.2,47.9$ & \\
\hline \multicolumn{7}{|l|}{ Mother's age at marriage in years } \\
\hline$<15$ & 42.4 & $36.4,48.6$ & $p=0.001$ & 33.4 & $27.7,39.7$ & $p=0.009$ \\
\hline $15-19$ & 37.5 & $34.5,40.5$ & & 28 & $25.4,30.7$ & \\
\hline $20-24$ & 27.0 & $23.1,31.2$ & & 21.4 & $17.0,26.5$ & \\
\hline $25-40$ & 32.4 & $20.3,47.5$ & & 21.2 & $12.3,34.1$ & \\
\hline \multicolumn{7}{|l|}{ Mother's current age in years } \\
\hline $15-19$ & 37.8 & $29.6,46.8$ & $P=0.022$ & 25.6 & $19.3,33.3$ & $p=0.052$ \\
\hline $20-24$ & 31.6 & $28.1,35.2$ & & 22.9 & $19.8,26.2$ & \\
\hline $25-29$ & 34.9 & $30.4,39.7$ & & 29.5 & $25.2,34.1$ & \\
\hline $30-34$ & 42.1 & $36.2,48.2$ & & 30.4 & $25.2,36.2$ & \\
\hline $35-49$ & 42.6 & $34.8,50.7$ & & 30.3 & $23.4,38.3$ & \\
\hline \multicolumn{7}{|l|}{ Mother's BMI } \\
\hline Normal & 36.2 & $33.5,38.9$ & $p=0.000$ & 26.4 & $23.6,29.4$ & $p=0.000$ \\
\hline Underweight & 44.5 & $38.6,50.5$ & & 42.7 & $36.8,48.9$ & \\
\hline Obese & 23.8 & $18.8,29.7$ & & 10.7 & $7.6,14.9$ & \\
\hline \multicolumn{7}{|l|}{ Mother's anemia } \\
\hline Not anemic & 35.7 & $32.4,39.0$ & $p=0.927$ & 24.9 & $21.9,28.0$ & $p=0.017$ \\
\hline Anemic & 35.9 & $32.6,39.3$ & & 29.7 & $26.5,33.1$ & \\
\hline \multicolumn{7}{|l|}{ Caste } \\
\hline Brahmin/Chettri & 34.7 & $31.1,38.6$ & $p=0.044$ & 24.1 & $21.0,27.5$ & $p=0.000$ \\
\hline Terai/Madhesi other & 41.9 & $36.3,47.6$ & & 37.1 & $32.2,42.4$ & \\
\hline Dalit & 39.1 & $32.6,46.0$ & & 30.8 & $24.5,37.8$ & \\
\hline Newar/Janajatis & 31.7 & $27.2,36.5$ & & 20.0 & $16.0,24.6$ & \\
\hline Muslim/other & 34.7 & $27.2,43.0$ & & 33.8 & $21.8,48.4$ & \\
\hline \multicolumn{7}{|l|}{ Mother's education } \\
\hline Illiterate & 45.8 & $41.9,49.8$ & $p=0.000$ & 36.8 & $32.5,41.3$ & $p=0.000$ \\
\hline Primary & 36.7 & $32.2,41.5$ & & 27.9 & $23.7,32.5$ & \\
\hline Secondary & 30.2 & $26.9,33.7$ & & 21.4 & $18.2,24.9$ & \\
\hline Higher & 22.4 & $17.6,28.1$ & & 14.8 & $11.0,19.7$ & \\
\hline \multicolumn{7}{|l|}{ Father's education } \\
\hline Illiterate & 46.3 & $39.9,52.8$ & $p=0.000$ & 38.1 & $32.3,44.3$ & $p=0.000$ \\
\hline Primary & 40.3 & $35.6,45.2$ & & 30.2 & $25.3,35.7$ & \\
\hline Secondary & 33.9 & $30.7,37.3$ & & 24.8 & $21.8,28.0$ & \\
\hline Higher & 25.3 & $20.6,30.7$ & & 19.6 & $15.4,24.7$ & \\
\hline
\end{tabular}


Table 2 Rate of stunting and underweight by predictors (Continued)

\begin{tabular}{|c|c|c|c|c|c|c|}
\hline Variables & Stunting (\%) & $95 \% \mathrm{Cl}$ & $p$-value & Underweight (\%) & $95 \% \mathrm{Cl}$ & $p$-value \\
\hline \multicolumn{7}{|l|}{ Mother's education } \\
\hline Not working & 30.0 & $26.5,33.8$ & $p=0.000$ & 24.9 & $21.2,29.0$ & $p=0.054$ \\
\hline Agriculture & 40.6 & $37.2,44.0$ & & 30.2 & $26.9,33.6$ & \\
\hline Paid jobs & 36.8 & $30.5,43.5$ & & 23.3 & $17.9,29.8$ & \\
\hline \multicolumn{7}{|l|}{ Wealth quintile } \\
\hline Poorest & 49.1 & $44.2,54.1$ & $p=0.000$ & 33.0 & $28.2,38.3$ & $p=0.000$ \\
\hline Poorer & 38.3 & $33.6,43.2$ & & 27.8 & $23.3,32.8$ & \\
\hline Middle & 35.4 & $30.3,40.9$ & & 32.8 & $27.4,38.5$ & \\
\hline Richer & 32.4 & $27.6,37.5$ & & 23.6 & $19.2,28.6$ & \\
\hline Richest & 17.6 & $13.2,23.0$ & & 12.9 & $8.7,18.7$ & \\
\hline \multicolumn{7}{|c|}{ Exposure to mass media (newspaper/radio/television) } \\
\hline Not at all & 50.5 & $45.7,55.3$ & $p=0.000$ & 39.7 & $34.0,45.7$ & $p=0.000$ \\
\hline Less than once a week & 32.1 & 28.9,35.4 & & 22.9 & $20.1,26.1$ & \\
\hline At least once a week & 30.4 & 27.0,33.9 & & 24.0 & $20.5,27.9$ & \\
\hline \multicolumn{7}{|l|}{ Sex of the children } \\
\hline Male & 35.9 & $32.8,39.1$ & $p=0.953$ & 27.0 & $24.2,30.0$ & $p=0.921$ \\
\hline Female & 35.8 & $32.4,39.3$ & & 27.2 & $24.0,30.8$ & \\
\hline \multicolumn{7}{|l|}{ Age of the children } \\
\hline 0-11 months & 16.4 & $12.7,20.8$ & $p=0.000$ & 18.5 & $14.8,23.0$ & $P=0.001$ \\
\hline $12-23$ months & 37.7 & $32.7,43.0$ & & 28.9 & $24.2,34.1$ & \\
\hline 24-35 months & 44.8 & $40.0,49.7$ & & 31.1 & $26.5,36.0$ & \\
\hline 36-47 months & 39.8 & $35.0,44.8$ & & 26.5 & $22.3,31.2$ & \\
\hline 48-59 months & 40.8 & $35.3,46.4$ & & 30.7 & $25.8,36.1$ & \\
\hline \multicolumn{7}{|l|}{ Place of residence } \\
\hline Urban & 31.9 & $28.7,35.3$ & $p=0.001$ & 23.6 & $20.7,26.9$ & $p=0.005$ \\
\hline Rural & 40.2 & $36.6,44.0$ & & 31.0 & $27.1,35.1$ & \\
\hline \multicolumn{7}{|l|}{ Ecological region } \\
\hline Mountain & 46.8 & $38.8,54.9$ & $p=0.011$ & 28.2 & $21.2,36.6$ & $p=0.000$ \\
\hline Hill & 32.7 & $29.1,36.6$ & & 18.8 & $15.9,22.0$ & \\
\hline Terai & 36.5 & $33.2,40.0$ & & 32.4 & $29.0,36.0$ & \\
\hline \multicolumn{7}{|l|}{ Province } \\
\hline Province 1 & 32.7 & $27.1,38.8$ & $p=0.001$ & 24.4 & $18.4,31.5$ & $p=0.000$ \\
\hline Province 2 & 36.6 & $32.8,40.6$ & & 36.6 & $31.6,42.0$ & \\
\hline Province 3 & 30.7 & $23.9,38.5$ & & 14.5 & $9.2,22.1$ & \\
\hline Province 4 & 29.0 & $22.1,37.0$ & & 15.4 & $10.6,22.0$ & \\
\hline Province 5 & 38.0 & $31.0,45.5$ & & 27.2 & $21.9,33.3$ & \\
\hline Province 6 & 54.9 & $48.6,61.1$ & & 36.4 & $30.8,42.4$ & \\
\hline Province 7 & 35.4 & $29.4,42.0$ & & 27.2 & $22.8,32.1$ & \\
\hline \multicolumn{7}{|l|}{ Household food security } \\
\hline Food secure & 29.7 & $26.2,33.5$ & $p=0.000$ & 22.4 & $19.1,26.2$ & $p=0.003$ \\
\hline Mild food insecure & 35.7 & $31.4,40.2$ & & 27.4 & $23.4,31.9$ & \\
\hline Moderate food insecure & 41.4 & $36.7,46.2$ & & 31.1 & $26.9,35.6$ & \\
\hline Severe food insecure & 46.4 & $38.3,54.7$ & & 34.9 & $26.5,44.4$ & \\
\hline
\end{tabular}


Table 3 Results from logistic regression analysis for the likelihood of stunting in underfive children

\begin{tabular}{lll}
\hline Variables & Adjusted Odds ratio & $\mathbf{9 5 \% ~ C l}$ \\
\hline Order $1 \&<12$ month of IBMFB & Reference group & \\
Order 1 \& 12-24 months of IBMFB & $0.6^{*}$ & $0.4-0.9$ \\
Order 1 \& 25-36 months of IBMFB & 0.7 & $0.4-1.2$ \\
Order 1 \& > 36 months of IBMFB & 0.6 & $0.3-1.0$ \\
Order 2-3 \& < =24 months of IBBSB & 0.9 & $0.6-1.4$ \\
Order 2-3 \& > 24 months of IBBSB & 0.8 & $0.5-1.1$ \\
Order > 3 \& < =24 months of IBBSB & 1.3 & $0.6-2.5$ \\
Order > 3 \& > 24 months of IBBSB & 0.9 & $0.5-1.6$
\end{tabular}

Mother's age at marriage in years

$<15$

15-19

20-24

25-40

Mother's current age in years

$\begin{array}{ll}15-19 & \text { Reference group } \\ 20-24 & 0.6^{*} \\ 25-29 & 0.6 \\ 30-34 & 0.8 \\ 35-49 & 0.6\end{array}$

\section{Mother's BMI}

Normal

Underweight

Obese

Mother's anemia

Not anemic

Anemic

\section{Caste}

Brahmin/Chettri

Terai/Madhesi other

Dalit

Newar/Janajatis

Muslim/other

Mother's education

Illiterate

Primary

Secondary

Higher

Father's education

Illiterate
Primary
Secondary
Higher

Higher

\section{Mother's occupation}

Not working

Agriculture

Reference group
1.1
0.8
1.3

Reference group

1.3

$0.6^{*}$

Reference group

1.0

Reference group

1.3

1.0

0.9

0.9

Reference group

0.8

0.9

0.9

0.8

Reference group

1.0

1.0

0.9

Reference group

1.1
0.8-1.4

$0.5-1.3$

$0.4-0.9$
$0.4-1.1$
$0.4-1.6$
$0.3-1.3$

$1.0-1.7$

$0.4-0.9$

$0.8-2.1$

$0.6-1.2$

$0.6-1.5$

$0.6-1.1$

$0.7-1.3$

$0.5-1.4$

$0.7-1.5$

$0.7-1.4$

0.6-1.6
Table 3 Results from logistic regression analysis for the likelihood of stunting in underfive children (Continued)

\begin{tabular}{lll}
\hline Variables & Adjusted Odds ratio & $\mathbf{9 5 \% ~ C l}$ \\
\hline Paid jobs & $1.7^{* *}$ & $1.2-2.4$ \\
Wealth quintile & & \\
Poorest & Reference group & \\
Poorer & $0.7^{*}$ & $0.5-0.9$ \\
Middle & $0.6^{* *}$ & $0.4-0.8$ \\
Richer & $0.5^{* *}$ & $0.3-0.8$ \\
Richest & $0.3^{* * *}$ & $0.2-0.6$
\end{tabular}

Exposure to mass media (newspaper/radio/television)

Not at all

Reference group

Less than once a week

$0.6^{* *}$

$0.5-0.9$

At least once a week

$0.6^{* * *}$

$0.5-0.8$

Sex of the children

Male

Reference group

Female

0.9

$0.7-1.1$

\section{Age of the children}

0-11 months

12-23 months

24-35 months

36-47 months

48-59 months

Place of residence

Urban

Rural

Ecological region

Mountain

0.8-1.3 Hill

Terai

Reference group

$3.2^{* * *}$

$2.2-4.6$

$4.8^{* * *}$

$3.3-7.1$

$3.7^{* * *}$

2.4-5.6

$3.8^{* * *}$

$2.5-5.8$

Reference group

1.1

$0.9-1.4$

Reference group

0.8

$0.5-1.2$

1.1

$0.7-1.8$

\section{Province}

Province 1

Reference group

0.6-1.5 Province 2

0.7

$0.4-1.0$

Province 3

1.1

$0.7-1.6$

Province 4

1.1

$0.7-1.8$

Province 5

1.1

$0.7-1.6$

Province 6

$1.8^{* *}$

$1.1-2.7$

Province 7

0.8

$0.5-1.2$

Household food security

0.6-1.1 Food secure

Reference group

Mild food insecure

1.0

$0.7-1.3$

Moderate food insecure

$0.8-1.5$

Severe food insecure

1.1

$0.8-1.8$

*** $p<0.001,{ }^{* *} p<0.01, * p<0.05$

1.2

large-scale survey in India to investigate the relationship between birth interval and childhood undernutrition also reported a $28 \%$ increase in stunting and $26 \%$ increase in 
Table 4 Results from logistic regression analysis for the likelihood of underweight in underfive children

Variables
Order $1 \&<12$ month of IBMFB
Order $1 \&$ 12-24 months of IBMFB
Order $1 \& 25-36$ months of IBMFB
Order $1 \&>36$ months of IBMFB
Order $2-3 \&<=24$ months of IBBSB
Order $2-3 \&>24$ months of IBBSB
Order $>3 \&<=24$ months of IBBSB
Mother's age at marriage in years
$<15$
15-19
$20-24$
$25+$

\section{Mother's current age in years}

$$
\begin{aligned}
& 15-19 \\
& 20-24 \\
& 25-29 \\
& 30-34 \\
& 35+
\end{aligned}
$$

\section{Mother's BMI}

Normal

Underweight

Obese

\section{Mother's anemia}

$$
\begin{aligned}
& \text { Not anemic } \\
& \text { Anemic }
\end{aligned}
$$

\section{Caste}

\section{Brahmin/Chettri}

Terai/Madhesi other

Dalit

Newar/Janajatis

Muslim/other

\section{Mother's education}

Illiterate

Primary

Secondary

Higher

\section{Father's education}

Illiterate
Primary
Secondary
Higher

Mother's education

Odds ratio
Reference group
1.3
1.2
0.9
1.2
1.1
1.4
Reference group
0.9
0.9
1.4
$95 \% \mathrm{Cl}$

$0.8-2.1$

$0.6-2.2$

$0.5-1.7$

$0.7-2.1$

$0.7-1.7$

$0.7-2.7$

$0.7-1.3$

$0.6-1.6$

$0.6-3.4$

Reference group

1.0

1.3

1.4

1.2

Reference group

$1.7^{* * *}$

$0.4^{* * *}$

Reference group

1.0

Reference group

1.0
1.0
0.8
0.8

Reference group

0.9

1.0

0.7

0.9

Reference group

1.0

1.0

1.0

$0.8-2.3$

$0.8-2.6$

$1.3-2.2$

$0.3-0.7$

$0.8-1.2$

$0.4-1.5$
Table 4 Results from logistic regression analysis for the likelihood of underweight in underfive children (Continued)

\begin{tabular}{lll}
\hline Variables & Odds ratio & $\mathbf{9 5 \% ~ C l}$ \\
\hline Not working & Reference group & \\
Agriculture & 1.2 & $0.9-1.6$ \\
Paid jobs & 1.3 & $0.9-2.0$ \\
Wealth quintile & & \\
Poorest & Reference group & \\
Poorer & $0.6^{*}$ & $0.4-0.9$ \\
Middle & 0.7 & $0.4-1.1$ \\
Richer & $0.5^{* *}$ & $0.3-0.8$ \\
Richest & $0.4^{* *}$ & $0.2-0.8$
\end{tabular}

Exposure to mass media (newspaper/radio/television)

Not at all

Less than once a week

Reference group

At least once a week

0.8

$0.5-1.0$

Sex of the children

0.6-1.5 Male

Female

$0.8-1.2$

Age of the children

0.6-2.5 0-11 months

12-23 months

24-35 months

36-47 months

48-59 months

0.7

$0.5-1.0$

Place of residence

Urban

Rural

Reference group

1.0

$0.8-1.2$

Reference group

$1.6^{* *}$

$1.2-2.2$

$1.9^{* * *}$

$1.3-2.7$

1.4

$0.9-2.0$

$1.9^{* *}$

1.3-2.7

\section{Ecological region}

Mountain

0.7-1.6 Hill

0.6-1.4 Terai

Reference group

1.1

$0.9-1.5$

0.5-1.1 Province

Province 1
Province 2
Province 3
Province 4
Province 5
Province 6
Province 7

Reference group

$\begin{array}{ll}0.9 & 0.6-1.4 \\ 1.8^{*} & 1.1-3.0\end{array}$

Reference group

$\begin{array}{ll}1.0 & 0.6-1.7 \\ 0.7 & 0.5-1.2 \\ 0.8 & 0.5-1.4 \\ 1.0 & 0.6-1.5 \\ 1.5 & 0.9-2.3 \\ 0.9 & 0.6-1.3\end{array}$

Household food security

\begin{tabular}{lll} 
Food secure & Reference group & \\
Mild food insecure & 0.9 & $0.6-1.2$ \\
Moderate food insecure & 1.0 & $0.7-1.4$ \\
Severe food insecure & 1.2 & $0.7-1.8$ \\
\hline$* * * 0.001,{ }^{* *} p<0.01,{ }^{*} p<0.05$ & &
\end{tabular}


underweight for those children born with a birth interval of $<24$ months [25].

\section{Factors associated with stunting and underweight}

This study showed significantly lower odds of stunting only in children with birth order one and 12-24 months of IBMFB than those children with birth order one and < 12 months of IBMFB. However, the present study did not yield a significant relationship between $\mathrm{PoB}$ and underweight. The result of a retrospective study analyzing the 2002-2003 El Salvador NFHS data to examine the relationship between birth spacing and childhood undernutrition also showed significantly higher odds of stunting in birth intervals of $<24$ months (OR 1.52, 95\% CI 1.21-1.92) and intervals of 25-35 months (OR 1.30, 95\% CI 1.05-1.64) than intervals of 36-59 months [23]. As in the present study, this study also did not show a significant relationship between birth interval and underweight. Peter et al. reported birth interval as a significant predictor of child stunting in a cross-sectional study that aimed to measure the prevalence and identify the predictors of undernutrition in children age 0-59 months in Hyderabad, India (OR 1.82, 95\% CI 1.033.21) [31].

The result of the multivariate logistic regression in the present study showed that low BMI was not significantly associated with stunting. However, low BMI mothers had significantly higher odds of underweight children than mothers with normal BMI. In contrast, a crosssectional study examining the factors associated with child stunting and underweight in 35 low-and middleincome countries showed significantly increased odds of child stunting (OR 1.6, 95\% CI 1.6-1.7, $p<0.001$ ) in mothers with low BMI [32]. A significant association was also observed for underweight (OR 2.3, 95\% CI 2.12.4, $p<0.001$ ) [32]. Nahar et al., in their case-control study, also reported that severely underweight children were more likely to have underweight mothers (AOR 3.8, 95\% CI 2.6-5.4) [33]. A cross-sectional study conducted in ten slums of Hyderabad, India, to appraise caregiving practices and health and nutritional status of children under 5 years of age reported low BMI of mother to be the significant predictor of stunting (OR 1.99, 95\% CI 1.5-4.7) [31]. Another retrospective study by Yang et al. reported significantly decreased odds of stunting for obese mothers (OR 0.70, 95\% CI 0.61-0.79, $p<$ 0.001 ), which was consistent with the outcome of the present study (OR 0.6, 95\% CI 0.4-0.9, $p<0.05$ ) [34].

Mother's in the age group 20-24 years had a significantly lower odds of stunting than mothers in the age group 15-19 years in the present study. Another casecontrol study in Bangladesh that investigated the risk factors associated with severe underweight among young children aged 6-24 months also reported the mother's age $<19$ years as a strong risk factor to cause child underweight (AOR 3.0, 95\% CI 1.9-4.8) [33]. In contrast, Yang et al. reported significantly higher odds of stunting in the age group 20-30 (OR 1.18, 95\% CI 1.08-1.29, $p<$ 0.001) [34].

We obtained significantly lower odds of stunting and underweight in poorer, middle, richer, and the richest wealth quintile than those who were in the poorest wealth quintile. Li et al. also reported that the poorest household wealth was the strongest factor associated with both child stunting (OR 1.7, 95\% CI 1.6-1.8, $p<$ 0.001 ) and underweight (OR 1.2, 95\% CI 1.1-1.3, $p<$ 0.001) [32]. A retrospective study analyzing Uganda DHS to examine determinants of stunting in children under 5 years of age reported similar higher odds of stunting in the poorest wealth quintile (OR 1.73, 95\% CI1.45-2.06, $p \leq 0.001$ ) [34]. Another retrospective study analyzing NDHS data also reported higher odds of stunting among babies born to poorer families than those born to wealthier families (AOR 1.51, 95\% CI 1.23-1.87) [35].

The present study showed that children $>11$ months are a strong predictor of stunting and underweight. A community-based cross-sectional study that examined factors associated with underweight among children under 5 years of age in Eastern Nepal reported that children who were $>24$ months of age were more likely to be underweight than children $<24$ months (OR 2.72, 95\% CI 1.6-4.7) [36].

To our knowledge, this is one of the few studies in Nepal to examine the relationship between PoB and childhood undernutrition. However, this study has a few known limitations. We used the NDHS 2016 crosssectional survey data, but a causal relationship between the associated factors and outcome cannot be inferred from this study. There is a possibility of residual confounding.

\section{Conclusion}

The findings of the present study inferred that planning of birth has a protective effect on childhood undernutrition. PoB can increase the length of time between the marriage and first birth, birth intervals between the subsequent births, and can also limit the number of childbirths, thus enabling mothers to have an ample amount of time to recover physically and emotionally. Hence, mothers can improve their health and nutrition, which ultimately contributes to children's better nutritional status. In a country like Nepal, where $25 \%$ of the population lives below the absolute poverty line [37], a focus to uplift the economic status of these populations is quintessential to enable them to practice $\mathrm{PoB}$ as a strategy to mitigate childhood undernutrition. The wide geographical coverage and utilization of mass media across the country can also play a crucial role in informing and 
educating people on $\mathrm{PoB}$ and its importance to reduce childhood undernutrition. To sum up, this study provides some statistical evidence, which government authorities, plans and policymakers can use to advocate PoB strategies (integration of nutritional strategies with PoB interventions) to fight against childhood undernutrition. The government of Nepal can use the findings of this study as supportive evidence to formulate and execute evidence-based nutrition-related policies, plans, and programs.

\begin{abstract}
Abbreviations
AARR: Annual Average Rate of Reduction; AOR: Adjusted Odds Ratio; BMI: Body Mass Index; CAPI: Computer Assisted Personal Interview; CBS: Central Bureau of Statistics; Cl: Confidence Interval; DoHS: Department of Health Service; DHS: Demographic and Health Survey; GoN: Government of Nepal; IBBSB: Interval Between Birth and Subsequent Birth; IBMFB: Interval Between Marriage and First Birth; IRB: Institutional Review Board; IYCF: Infant and Young Children Feeding; KISAN: Knowledge-based Integrated Sustainable Agriculture in Nepal; OR: Odds Ratio; MoHP: Ministry of Health and Population; MSNP: Multi-Sector Nutrition Plan; NDHS: Nepa Demographic and Health Survey; NFHS: Nepal Family Health Survey; NHRC: Nepal Health Research Council; NPHC: Nepal Population and Housing Census; PoB: Planning of Birth; SABAL: Sustainable Action for Resilience and Food Security; SD: Standard Deviation; SUN: Scaling Up Nutrition; UN: United Nation; UNICEF: United Nations Children's Fund; USAID: United States Agency for International Development; WHA: World Health Assembly; WHO: World Health Organization
\end{abstract}

\section{Acknowledgements}

The authors extend their sincere appreciation to the DHS program for providing the NDHS datasets for the analysis.

\section{Authors' contributions}

IT conceptualized the study, supported analysis, drafted the original manuscript, validated, reviewed, edited and approved the final draft of the manuscript. KA conceptualized the study, analyzed the data, supported to draft the original manuscript, validated, reviewed, edited and approved the final draft of the manuscript. YP conceptualized the study, supported data analysis, validated, reviewed, edited and approved the final draft of the manuscript. BPS validated, reviewed, edited and approved the final draft of the manuscript. RBK validated, reviewed, edited and approved the final draft of the manuscript.

\section{Funding}

Not applicable.

\section{Availability of data and materials}

The datasets used and/or analyzed in the current study are available from the DHS program (http://www.dhsprogram.com/data/available-datasets.cfm) on reasonable request.

\section{Ethics approval and consent to participate}

The NDHS 2016 was reviewed by the ICF institutional review board. Plus, the survey also received ethical approval from the NHRC.

We performed a secondary analysis of the NDHS 2016 datasets. The original survey (NDHS 2016) received informed consent from all the participants in the survey. Written informed consent for participants in the study was also obtained as per NHRC guidelines; data were publicly available and did not include individual identities and thus did not require ethics approval.

\section{Consent for publication}

Not applicable.

\section{Competing interests}

The authors declare that they have no competing interests.

\section{Author details}

${ }^{1}$ Health for Life, RTI International, Kathmandu, Nepal. ${ }^{2}$ New ERA, Rudramatimarg, Kalopul, Kathmandu, Nepal. ${ }^{3}$ School of Public Health, University of Alberta, Edmonton, Canada. ${ }^{4}$ Ministry of Health and Population, Ram Shah Path, Kathmandu, Nepal. ${ }^{5}$ Center for International Health, Ludwig Maximilian University of Munich (CIH-LMU), Munich, Germany. ${ }^{6}$ Centre of Population and Development, Purbanchal University, Munich, Nepal.

Received: 3 July 2020 Accepted: 18 November 2020

Published online: 25 November 2020

References

1. Ahmed T, Hossain M, Sanin Kl. Global burden of maternal and child undernutrition and micronutrient deficiencies. Ann Nutr Metab. 2012; 61(suppl 1):8-17.

2. Swaminathan S, Hemalatha R, Pandey A, Kassebaum NJ, Laxmaiah A, Longvah $\mathrm{T}$, et al. The burden of child and maternal malnutrition and trends in its indicators in the states of India: the global burden of disease study 1990-2017. Lancet Child Adolesc Health. 2019;3(12):855-70.

3. Black RE, Allen LH, Bhutta ZA, Caulfield LE, de Onis M, Ezzati M, et al. Maternal and child undernutrition: global and regional exposures and health consequences. Lancet (London, England). 2008;371(9608):243-60 Available from: http://www.ncbi.nlm.nih.gov/pubmed/18207566. Cited 2020 May 4.

4. Karn S, Adhikari D, Paudyal N, Aryal B, Adhikari RK, Steffen MM. Child undernutrition and feeding practices in Nepal: Trends, inequities, and determinants. DHS Furth Anal Reports No 122; 2019. p. 122. Available from: http://dhsprogram.com/pubs/pdf/FA122/FA122.pdf.

5. [NPC]National Planning Commission. Nepal's Sustainable Development Goals, Baseline Report. Natl Plan Comm. 2017. p. 120 Available from: https:// www.npc.gov.np/images/category/SDGs_Baseline_Report_final_29_June-1 (1).pdf. Accessed 29 May 2020.

6. UNICEF. The Scaling Up Nutrition (SUN) Movement Annual Progress Report 2018. Annu Prog Rep. 2018. p. 1-200.

7. Commission NP. Multi-Sector Nutrition Plan. 2018;(November 2017).

8. Policy N. Global database on the Implementation of Nutrition Action. 2015; (October):1-9.

9. FAO \& WHO. Towards country-specific smart commitments for action on nutrition; 2016. p. 4. Available from: http://www.who.int/nutrition/decade-ofaction/smart_commitments.pdf?ua $=1$

10. United Nations. The sustainable development goals report 2019. United Nations Publ Issued by Dep Econ Soc Aff. 2019;64:1-64.

11. Dhimal M, Dhimal ML, Pote-Shrestha RR, Groneberg DA, Kuch U. Healthsector responses to address the impacts of climate change in Nepal. WHO South-East Asia J Public Health. 2017:6(2):9-14.

12. Ministry of Health and Population (MOHP) [Nepal], New ERA, and Macro International Inc. Nepal demographic and health survey 2006. Kathmandu: Ministry of Health and Population, New ERA, and Macro International Inc; 2007.

13. Ministry of Health and Population-MOHP/Nepal, New ERA/Nepal, and IC International. Nepal demographic and health survey 2011. Kathmandu: MOHP/Nepal, New Era/Nepal, and ICF International; 2012.

14. Ministry of Health - MOH/Nepal, New ERA/Nepal, and ICF. Nepal demographic and health survey 2016. Kathmandu: MOH/Nepal, New ERA Nepal, and ICF; 2017.

15. Rana MJ, Gautam A, Goli S, Uttamacharya, Reja T, Nanda P, et al. Planning of births and maternal, child health, and nutritional outcomes: recent evidence from India. Public Health. 2019;169:14-25. https://doi.org/10.1016/j.puhe. 2018.11.019.

16. Rana MJ, Goli S. Family Planning and Its Association with Nutritional Status of Women: Investigation in Select South Asian Countries. Indian J Hum Dev. 2017;11(1):56-75 Available from: http://journals.sagepub.com/doi/10.1177/ 0973703017712392. Cited 2020 May 5.

17. Bongaarts J. Does Family Planning Reduce Infant Mortality Rates ? Popul Dev Rev. 2010;13(2):323-34 Published by : Population Council Stable URL http://www.jstor.org/stable/19731.

18. Ringheim K, Gribble J, Foreman M. Integrating family planning and maternal and child health care: saving lives, money, and time. Int Fam Plan Perspect. 2007;33(1):6-12.

19. Gavin L. The Integration of Family Planning with Other Health Services : A Literature Review Author ( $s$ ): Anne Sebert Kuhlmann, Loretta Gavin and 
Christine Galavotti Stable URL : https://www.jstor.org/stable/41038666 Linked references are available on JSTOR for . 2020;36(4):189-96.

20. Rana MJ, Goli S. Does planning of births affect childhood undernutrition? Evidence from demographic and health surveys of selected south Asian countries. Nutrition. 2018;47:90-6. https://doi.org/10.1016/j.nut.2017.10.006.

21. Cunningham K, Singh A, Pandey Rana P, Brye L, Alayon S, Lapping K, et al. Suaahara in Nepal: an at-scale, multi-sectoral nutrition program influences knowledge and practices while enhancing equity. Matern Child Nutr. 2017; 13(4):1-13.

22. Haselow NJ, Stormer A, Pries A. Evidence-based evolution of an integrated nutrition-focused agriculture approach to address the underlying determinants of stunting. Matern Child Nutr. 2016;12:155-68.

23. Gribble JN, Murray NJ, Menotti EP. Reconsidering childhood undernutrition: can birth spacing make a difference? An analysis of the 2002-2003 El Salvador National Family Health Survey. Matern Child Nutr. 2009:5(1):49-63.

24. Rutstein SO. Effects of preceding birth intervals on neonatal, infant and under-five years mortality and nutritional status in developing countries: Evidence from the demographic and health surveys. Int I Gynecol Obstet. 2005;89(SUPPL. 1).

25. Chungkham HS, Sahoo H, Marbaniang SP. Birth interval and childhood undernutrition: evidence from a large scale survey in India. Clin Epidemiol Glob Health. 2020;(December 2019):0-1. https://doi.org/10.1016/j.cegh.2020. 04.012.

26. Paudel D, Ahmed M, Pradhan A, Dangol RL. Successful use of tablet personal computers and wireless technologies for the 2011 Nepal demographic and health survey. Glob Health Sci Pract. 2013;1 (2):277-84.

27. Mgongo M, Chotta NAS, Hashim TH, Uriyo JG, Damian DJ, Stray-Pedersen B, et al. Underweight, stunting and wasting among children in Kilimanjaro region, Tanzania; a population-based cross-sectional study. Int J Environ Res Public Health. 2017;14(5):1-12.

28. Pakistan NI of PS, Inc MI. Pakistan Demographic Health Survey, 2017-2018. 2018. Available from: http://www.nips.org.pk/abstract_files/ PDHSFinalReportasofJan22-2014.pdf , https://dhsprogram.com/pubs/pdf/ FR354/FR354.pdf.

29. Ahsan KZ, Jamil K, Islam S, Al-Sabir ACN. Bangladesh demographic and health survey 2017-18: key indicators report; 2019.

30. Mal H, Program DHS, Rockville ICF. Maldives demographic and health survey 2016-17. 2016; Available from: https://dhsprogram.com/pubs/pdf/ FR349/FR349.pdf.

31. Peter R, Kumar KA. Prevalence and predictors of undernutrition in children aged 0-59 months in the slums of Hyderabad, India. 2014;(4).

32. Li Z, Kim R, Vollmer S, Subramanian SV. Factors associated with child stunting, wasting, and underweight in 35 low- and middle-income countries. JAMA Netw Open. 2020;3(4):e203386.

33. Nahar B, Ahmed T, Brown KH, Hossain MI. Risk factors associated with severe underweight among young children reporting to a diarrhoea treatment facility in Bangladesh. J Health Popul Nutr. 2010;28(5):476-83.

34. Yang YY, Kaddu G, Ngendahimana D, Barkoukis H, Freedman D, Lubaale YAM, et al. Trends and determinants of stunting among under-5s: evidence from the 1995, 2001, 2006 and 2011 Uganda demographic and health surveys. Public Health Nutr. 2018;21(16):2915-28.

35. Budhathoki SS, Bhandari A, Gurung R, Gurung A, Kc A. Stunting among under 5-year-olds in Nepal: trends and risk factors. Matern Child Health J. 2020;24(November 2019):39-47.

36. Adhikari D, Khatri RB, Paudel YR, Poudyal AK. Factors associated with underweight among under-five children in eastern Nepal: communitybased cross-sectional study. Front Public Health. 2017;5(December):1-9.

37. Central Bureau of Statistics. Nepal living standards survey 2010/11 statistical report volume one. 2012;(December).

\section{Publisher's Note}

Springer Nature remains neutral with regard to jurisdictional claims in published maps and institutional affiliations.

Ready to submit your research? Choose BMC and benefit from:

- fast, convenient online submission

- thorough peer review by experienced researchers in your field

- rapid publication on acceptance

- support for research data, including large and complex data types

- gold Open Access which fosters wider collaboration and increased citations

- maximum visibility for your research: over $100 \mathrm{M}$ website views per year

At BMC, research is always in progress.

Learn more biomedcentral.com/submissions 